\title{
Episodic Action Memory for Real Objects: An ERP Investigation With Perform, Watch, and Imagine Action Encoding Tasks Versus a Non-Action Encoding Task
}

\author{
Ava J. Senkfor ${ }^{1}$, Cyma Van Petten ${ }^{2}$, and Marta Kutas ${ }^{3}$
}

\begin{abstract}
Cognitive research shows that people typically remember actions they perform better than those that they only watch or imagine doing, but also at times misremember doing actions they merely imagined or planned to do (source memory errors). Neural research suggests some overlap between brain regions engaged during action production, motor imagery, and action observation. The present study evaluates the similarities/differences in brain activity during the retrieval of various types of action and nonaction memories. Participants study real objects in one of four encoding conditions: performing an action, watching the experimenter perform an action, or imagining an action with an object, or a nonmotoric task of estimating an object's cost. At test, participants view color
\end{abstract}

\section{INTRODUCTION}

After serving as editor for former president Reagan's memoir, Korda (1997) recounts "we had to convince Reagan not to include the story about how he recorded the atrocities at the German death camps ... a story that he had told Yitzhak Shamir, bringing tears to Shamir's eyes, because as it happens, Reagan had spent the entire war in Hollywood ... He had seen some of the first footage taken by Army cinematographers of the ... camps and had somehow convinced himself that he'd been there" (p. 93). Such public scrutiny of an individual's memory is rare, but laboratory studies suggest that confusions occur even in young healthy individuals (see Henkel, Johnson, \& De Leonardis, 1998, for review). Examining the brain activity during the encoding and retrieval of actions performed, observed, and imagined may help to clarify why such errors are possible, and yet not so prevalent as to be commonplace.

Performed, imagined, and watched actions, though different do share some features in common. Selfperformed actions, for example, while visually similar to observed actions, include additional attributes asso-

\footnotetext{
${ }^{1}$ NMR Center-Massachussetts General Hospital, Harvard Medical School, ${ }^{2}$ University of Arizona, ${ }^{3}$ University of CaliforniaSan Diego
}

photos of the objects, and make source memory judgments about the initial encoding episodes. Event-related potentials (ERPs) during test reveal (1) content-specific brain activity depending on the nature of the encoding task, and (2) a hand tag, i.e., sensitivity to the hand with which an object had been manipulated at study. At fronto-central sites, ERPs are similar for the three action-retrieval conditions, which are distinct from those to the cost-encoded objects. At occipital sites ERPs distinguished objects from encoding conditions with visual motion (Perform and Watch) from those without visual motion (Imagine and Cost). Results thus suggest some degree of recapitulation of encoding brain activity during retrieval of memories with qualitatively distinct attributes. ciated with agency such as formulating goals, creating motor programs, and receiving proprioceptive and tactile feedback. Performed and imagined actions likewise share features but tend to differ in the quality of the sensory experience and specificity of motor programs. Any of these informational sources thus could serve to distinguish memories for actions considered, carried out, or observed.

Hemodynamic, event-related potential (ERP), and single-unit data all have demonstrated some degree of overlap in the brain activity engendered by actual performance versus imagined performance of an action. Regional cerebral blood flow measurements have implicated the premotor and supplementary motor areas (SMA) but not the primary cortex in mental rehearsal of hand movements (Ingvar \& Philipsson, 1977; Roland, Larsen, Lassen, \& Skinhoj, 1980). Recent neuroimaging studies have (1) added the inferior parietal cortex to the list of areas that respond similarly in performance and imagery tasks; (2) suggest some (but not complete) differentiation between the specific premotor regions involved in these cases; (3) implicate Broca's area and prefrontal regions in motor imagery; and (4) indicate even primary motor cortex engagement by motor imagery, albeit less than during active performance (e.g., Binkofski et al., 2000; Rizzolatti, Fadiga, Gallese, \& Fogassi, 1996; Stephan et al., 1995; see Grezes \& Decety, 
2001, for meta-analysis and review). ERP studies, likewise, reveal similar (but not identical) slow negative potentials during preparation and "execution" of actual versus imagined motor sequences (Beisteiner, Hollinger, Lindinger, Lang, \& Berthoz, 1995; Cunnington, Iansek, Gradshaw, \& Phillips, 1996).

Neuroimaging studies in humans observing versus performing actions were inspired by the reported similarity in single-unit activity in premotor cortex (area F5) of macaques actively grasping and merely observing a grasping action (Di Pelligrino, Fadiga, Fogassi, Gallese, \& Rizzolatti, 1992). Studies with humans have yielded mixed results. Hari, Forss, Avikainen, Kirveskari, Salenius, and Rizzolatti (1998) and Schnitzler, Salenius, Salmelin, Jousmaki, and Hari (1997), e.g., inferred similar precentral motor cortex excitability from magnetoencephalographic records of individuals executing, imagining, and observing actions. Grafton, Arbib, Fadiga, and Rizzolatti (1996), however, observed increased blood flow in the dorsolateral prefrontal cortex during action imagination but not observation, although both activated the SMA compared to simple object viewing. Rizzolatti et al. (1996), by contrast, found an overlap in the posterior parietal cortex (BA 7) for actions executed and observed but none in the frontal lobes. The extant data thus point to commonalities as well as differences among the brain areas involved in motor execution, motor imagery, and observed actions compared to control tasks without actions.

Here, we focus on memory for actions by analyzing the electrical brain activity elicited when participants are cued by color photos of objects to retrieve a prior study episode and to decide whether they performed an action (Perform task), imagined (Imagine task), or watched the experimenter perform an action (Watch task) with it, or had made a realistic estimate of its purchase price (Cost task). The Cost task was designed to be demanding and to draw attention to the object's semantic but not somatomotor attributes.

Given the reported overlap in active brain regions during performance, imagination, and observation, we expected these encoding episodes to be more confusable and thus result in more memory errors than the non-action cost estimation task. However, we were especially interested in the ERPs in the four conditions when retrieval was successful so that we could examine the brain activity associated with the actual retrieval and differentiation of encoded information. To the extent that brain activity during successful retrieval recapitulates that during encoding, we expect to see the cortical motor association areas engaged during study reactivated at test; presumably, this would be reflected in a similarity of the ERPs elicited by objects encoded during action performance, imagination, and observation but not those during cost estimation. Moreover, the cost estimation condition serves as an important control for evaluating the proposal that memory traces with and without motor aspects are distinct (Backman, 1985; Engelkamp \& Zimmer, 1985; Heil et al., 1999). In its strongest form, the motor recapitulation bypothesis also predicts that retrieval ERPs will reflect the hand (right vs. left) that manipulated the object during encoding.

Even if the motor recapitulation hypothesis is not supported, the pattern of ERPs across the four conditions will shed light on the content-specificity of memory retrieval. The null hypothesis is that accurate retrieval from episodic source memory entails unitary, amodal processes that do not vary with memory attributes, or possibly that noninvasive ERPs will be insensitive to subtle variations in patterns of contentdependent contextual neural activity. However, as accurate recall of the different encoding conditions from study would seem to require retrieval of qualitatively different sensory, semantic, and motoric information, we expect these to be reflected in different ERP patterns.

The present paradigm has much in common with studies of reality monitoring wherein participants were asked to judge (in response to word cues) whether pictures were actually perceived, or merely imagined (Johnson, Kounios, \& Reeder, 1994), whether words were spoken aloud or silently, or just heard (Hashtroudi, Johnson, \& Chrosniak, 1990), and whether various action commands were performed, imagined, or observed (Cohen \& Faulkner, 1989). Reality monitoring paradigms are but one variant of a more general class of source memory paradigms wherein participants are queried about the relation between an item and its encoding context. Johnson, Hashtroudi, \& Lindsay (1993) note that the "self- versus other-generated" can be an important dimension for making source judgments based on their finding that individuals could more readily distinguish between a self-generated (imagination) and an other-generated event (observation) than between two self-generated events. A strict dichotomy between self and other contrasts with the motor action literature reviewed above by predicting that retrieval of memories with active participant involvement, overt (Perform, Cost) or covert (Imagine), will pattern together relative to retrieval of a memory wherein some "other"-the experimenter-performed the action (e.g., Observe). Finally, yet another pattern of results would be expected if source retrieval were based on the presence or absence of specific visual attributes. In that case, both Perform and Watch memories, which include visual motion as the objects are actively manipulated, would be distinct from Imagine and Cost memories wherein the objects are stationary.

Although content-specific memory processes have not been extensively investigated, previous ERP studies show that ERPs are sensitive to memory retrieval. ERPs in explicit recognition tests consistently show that 
correctly identified old items (hits) elicit more positivity than correctly identified new items (correct rejections) whether the items are printed or spoken words, line drawings, photographs, or novel geometric shapes (Van Petten, Senkfor, \& Newberg, 2000; Senkfor \& Van Petten, 1998; Schloerscheidt \& Rugg, 1997; Swick \& Knight, 1997; Van Petten \& Senkfor, 1996; Paller \& Kutas, 1992; Friedman, 1990). The late positivity further distinguishes hits from both unrecognized old items (misses) and falsely recognized new items (false alarms; Rubin, Van Petten, Glisky, \& Newberg, 1999; Van Petten \& Senkfor, 1996; Wilding \& Rugg, 1996; Neville, Kutas, Chesney, \& Schmidt, 1986). Old/new ERP differences typically begin 300-400 msec poststimulus onset, have a broad scalp distribution with a maximum over the temporal-parietal sites, and show a small left hemisphere preponderance (at least for verbal materials in right-handed subjects).

A few studies have also documented a second ERP old/new effect, prominent over the prefrontal sites. This effect appears in source memory tests when participants are asked to retrieve some aspect of the context in which the stimulus was initially experienced-whether a word is spoken in the same or different voice, a line drawing appears in the same or a different spatial location, a word occurs in the same modality (printed or spoken) or list as at study (Van Petten et al., 2000; Trott, Friedman, Ritter, \& Fabiani, 1997; Senkfor \& Van Petten, 1996, 1998; Wilding \& Rugg, 1996, 1997). Compared to new items, recognized old items in these experiments elicit the spatially widespread positivity typical of old/new recognition tests, together with a second later prefrontal positivity of longer duration that has specifically been linked to attempts to retrieve source information. The prefrontal scalp focus of this effect accords well with data showing that patients with frontal damage have greater impairments in source than item memory (Janowsky, Shimamura, \& Squire, 1989), and with correlations between source memory performance and tests sensitive to frontal function in healthy elderly adults (Glisky, Polster, \& Rothieaux, 1995).

Source memory paradigms offer an excellent opportunity for examining the content-specificity of retrieval processes as the same stimuli can be used to evoke memories of qualitatively different encoding episodes. This opportunity has not yet been well exploited as "sources" have been varied parametrically (e.g., same or different voice or location, List 1 vs. List 2) rather than qualitatively. There is no reason to expect qualitatively different neural processes to be engaged by the retrieval of a male versus a female voice, and indeed none have been found with such "sources" (Van Petten et al., 2000; Senkfor \& Van Petten, 1998).

Recently, we investigated item and source memory where source was based on qualitatively distinct aspects of encoding episodes (Senkfor, Van Petten, \& Kutas, submitted) and found that while the ERPs to photos of old items differed from those to new items, they did not distinguish between encoding tasks during a simple item recognition task. Encoding-task information thus does not seem to be accessed when it is not needed. In contrast, the ERPs over the frontal sites were sensitive to the type of retrieval task (item vs. source) while those over posterior sites distinguished successful retrieval of source information (action encoding vs. cost encoding). However, as our two encoding tasks differed in more than just their differential engagement of the motor system, we were limited in our explanation for the observed differences in brain activity. The present experiment is aimed at providing a more complete analysis by contrasting the contributions of motor activity (Perform and Imagine, perhaps Watch), visual motion (Perform and Watch), tactile contact (Perform only), and self-initiated activity (Perform, Imagine, and Cost).

At the study, participants received real objects (e.g., stapler) or toy versions of real objects (e.g., slot machine) one by one as they generated and Performed a typical action with it, Imagined performing a typical action with it, Watched the experimenter carry out a typical action with it, or generated and verbalized its purchase price (Cost). Encoding hand in the Perform, Imagine, and Watch conditions was cued by the side of the participant on which the object was placed. (Note: objects on the participant's right side were manipulated with the experimenter's left hand.) Actual contact between object and participant occurred on Perform trials only. At test, participants viewed digital images of all studied objects and indicated which of the four encoding tasks was employed for each. Electroencephalogram (EEG), performance accuracy, and reaction times were recorded and analyzed with factors of encoding task (Perform, Watch, Imagine, Cost), and ERP scalp distribution across four time windows, and, in some analyses, with an encoding hand factor to assess the strong form of the motor recapitulation hypothesis.

\section{RESULTS}

\section{Behavioral Performance}

As shown in Table 1, participants were fastest and most accurate in recalling the source when they actually performed some action with the object, and next best when they watched the experimenter do so [Perform vs. Watch, $F(1,15)=19.8, p=.0005$; Perform vs. Imagine, $F(1,15)=22.5, p<.0005$; Perform vs. Cost, $F(1,15)=$ 41.4, $p<.0001]$. Source memory for Watch-encoded objects was more accurate than for Imagined or Costencoded objects $[F \mathrm{~s}(1,15)=9.23,19.3, \mathrm{ps}<.01$, .0005, respectively, which are equivalent $(F<2.0)]$. Correct reaction times reveal a similar pattern. Source decisions about perform items are faster than those about watch, 
Table 1. Reaction Times and Accuracies in the Memory Test

\begin{tabular}{lcc}
\hline Encoding Task & Reaction Time (msec) & Accuracy (\%) \\
\hline Perform & $\mathbf{1 5 4 6 ( 4 7 )}$ & $\mathbf{9 3}(\mathbf{1 . 1})$ \\
Right & $1548(48)$ & $93(1.7)$ \\
Left & $1537(43)$ & $94(1.4)$ \\
Watch & $\mathbf{1 6 5 1}(\mathbf{5 8 )}$ & $\mathbf{8 8}(\mathbf{1 . 1})$ \\
Right & $1658(62)$ & $89(1.2)$ \\
Left & $1645(57)$ & $88(1.5)$ \\
Imagine & $\mathbf{2 0 7 2}(\mathbf{9 9})$ & $\mathbf{8 2}(\mathbf{2 . 5})$ \\
Right & $2082(93)$ & $83(2.4)$ \\
Left & $2124(90)$ & $81(2.5)$ \\
Cost & $\mathbf{1 7 6 2 ( 5 9 )}$ & $\mathbf{7 8}(\mathbf{2 . 6})$ \\
Right & $1753(57)$ & $77(3.0)$ \\
Left & $1787(67)$ & $78(2.3)$ \\
\hline
\end{tabular}

Standard error in parentheses. Right and left refer to the location of objects during the study phase, which correspond to the cued hand for object manipulation (or imagined manipulation) in the three action tasks.

imagine, or cost-encoded items, $F^{\prime} s(1,15)=9.03$, 46.4, and 34.8, p's <.01, .0001, and .0001, respectively, with watch items responded to faster than imagine and cost items, F's $(1,15)=33.3$ and 5.52, p's < .0001 and .05, respectively. Finally, although the cost and imagine encoding tasks yield equivalent accuracies, cost judgments are faster, $F(1,15)=21.7, p<.0005$. Neither accuracy nor reaction time differed as a function of object manipulation hand $(F<1.5)$.

Table 2 summarizes the types of errors (source misattributions) that participants made. Log linear models are used to examine the pattern of errors after excluding correct responses (Brown, 1988). The first model using the factors of encoding task, response at test, and their interaction indicated that errors are not uniformly distributed across the cells in Table 2. The encoding task factor is significant (chi-square $=160.8$, $d f=3, p<.0001$ ), thus, some encoding conditions elicit fewer source errors than others do. This conclusion echoes the accuracy analyses reported above. The significant effect of response at test factor (chi-square $=$ 110.9, $d f=3, p<.0001)$ indicates that errors are not equally distributed across the alternative response options: Participants are most likely to respond "imagine" when wrong and least likely to respond "cost" when wrong. Finally, a significant Encoding Task $\times$ Response Task interaction indicates that some source confusions are more likely than others (chi-square $=56.3, d f=5$, $p<.0001$ ). Additional log linear models using only the encoding task factor, or only the response factor were evaluated for the source of this interaction (e.g., most prevalent source confusions, given the overall accuracy differences among conditions or bias to respond "imagine" when in error). Both models indicate two confusions as the least likely to have occurred by chance: Cost-encoded items judged as Imagined $\left(G^{2}\right.$ 's $>68.2$, $d f=7, p<.00001)$ and Imagine-encoded items judged as Watched ( $G^{2}$ 's $\left.>40.7, d f=6, p<.00001\right)$. The two models did not converge in identifying any other source of confusions as unusually frequent.

\section{ERPs}

Figure 1 shows the ERPs elicited by object images for which participants correctly remember the encoding task versus those they misremember, collapsed across encoding tasks. Correct and incorrect source trials are associated with similar ERPs prefrontally, but at more posterior sites, correct source trials elicit more positive ERPs beginning around $600 \mathrm{msec}$ poststimulus onset. These data are quantified as mean amplitudes from 600 to 1400 msec, relative to a 100-msec prestimulus baseline. Measurements from 24 lateral electrode sites are

Table 2. Response Frequencies by Encoding Task Across All Subjects

\begin{tabular}{|c|c|c|c|c|c|c|}
\hline \multirow[b]{2}{*}{ Encoding Task } & \multicolumn{4}{|c|}{ Test Responses } & \multirow[b]{2}{*}{ Total } & \multirow[b]{2}{*}{ Error } \\
\hline & Perform & Watch & Imagine & Cost & & \\
\hline Perform & 1507 & 44 & 34 & 30 & 1615 & 108 \\
\hline Watch & 65 & 1399 & 86 & 27 & 1577 & 178 \\
\hline Imagine & 82 & 135 & 1302 & 61 & 1580 & 278 \\
\hline Cost & 77 & 62 & 205 & 1236 & 1580 & 344 \\
\hline Total & 1731 & 1640 & 1627 & 1354 & 6352 & \\
\hline Errors & 224 & 241 & 325 & 118 & & \\
\hline
\end{tabular}

Correct responses (in bold type) lie on the diagonal. 
Figure 1. Grand average ERPs to correctly remembered encoding task trials (Hit) versus incorrectly remembered trials (Miss) from the prefrontal, central, parietal, and occipital midline sites. Negative voltage is plotted upward here and in all subsequent figures.

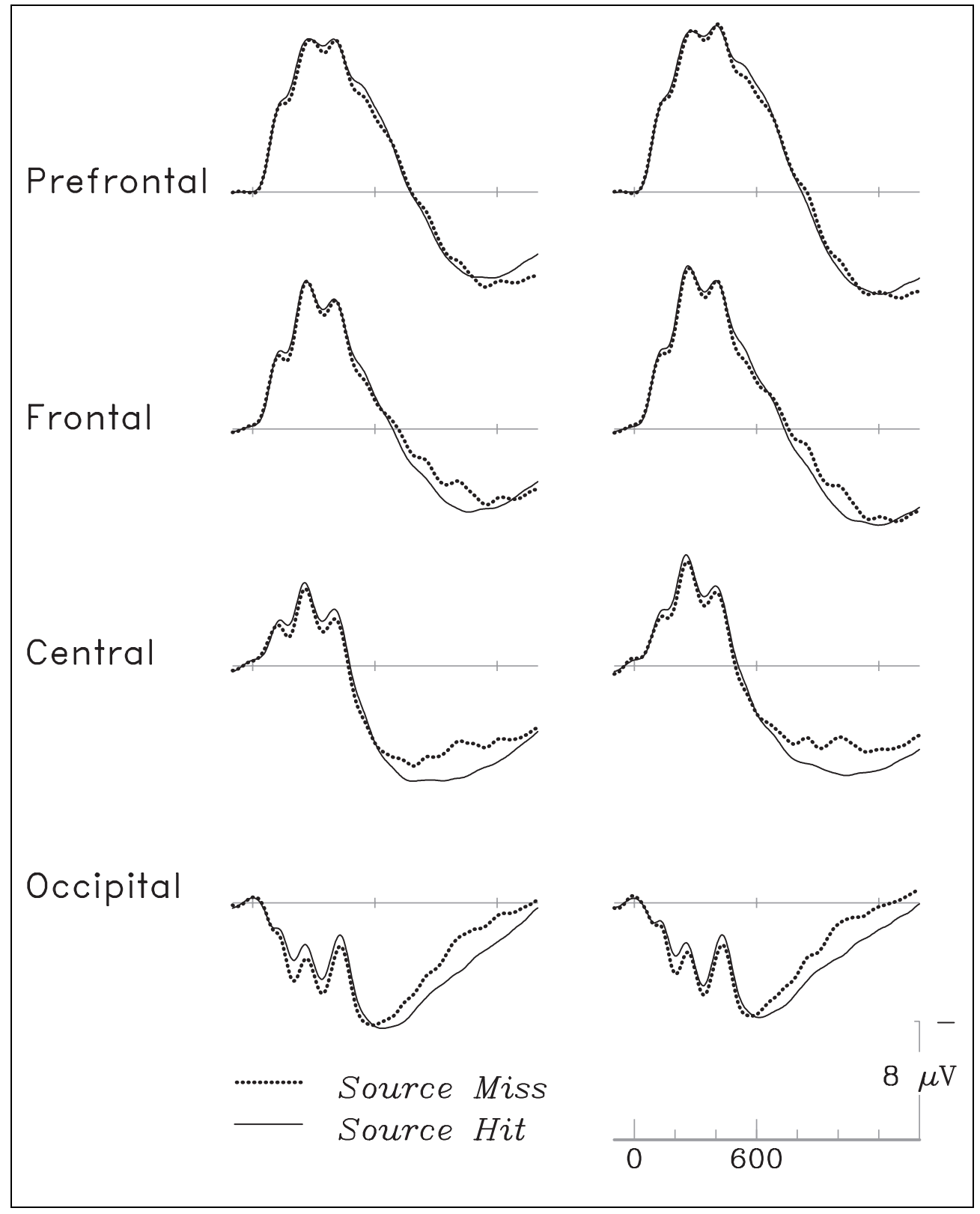

subjected to a repeated measure analysis of variance (ANOVA) with accuracy (source hits vs. misses), electrode site along the Anterior-Posterior axis (AP, four levels), along the lateral axis [medial, dorsal, lateral (MDL)], and Hemisphere (right vs. left) as factors. The main effect of source accuracy only approaches significance, $F(1,15)=3.45, p<.10$. However, a significant accuracy by $\mathrm{AP}$ interaction, $F(3,45)=7.69, p=.01, e=$ .48 , reflects the absence of a difference over the prefrontal sites, and greater positivity over more posterior sties when the encoding tasks were correctly identified. Inadequate signal-to-noise ratio precludes us from separating and comparing error trials by encoding task.

ERPs elicited by the object images accompanied by correct decisions about the encoding task are shown in Figure 2. The four ERPs are indistinguishable for the first $600 \mathrm{msec}$ following stimulus onset. Thereafter, the four conditions differ from each other, but the patterns of differences vary with scalp location and time after stimulus onset. Objects from the Imagine task elicit more positive ERPs than all other conditions at the most anterior (prefrontal) sites. ERPs to the objects from the cost task are distinct from the three action conditions (which resemble one another), at fronto-central sites. Finally, there is a clustering of ERPs to the objects from the Perform and Watch versus Imagine and Cost estimate tasks at posterior parietal, temporal, and occipital sites.

The behavioral data show a clear gradient of memorability across the four encoding tasks-perform $>$ watch $>$ imagine $>$ cost - that it not reflected in a similar gradient of positivity when all of the latency ranges and scalp regions are considered. Source memory effects vary across time, thus mean amplitudes are measured 
Figure 2. Grand average ERPS elicited by photographs of correctly identified objects encoded with Perform, Watch, Imagine, or Cost tasks, at all 28 scalp sites. The ERPs are displayed in an approximate 2-D representation of the scalp electrode placements.

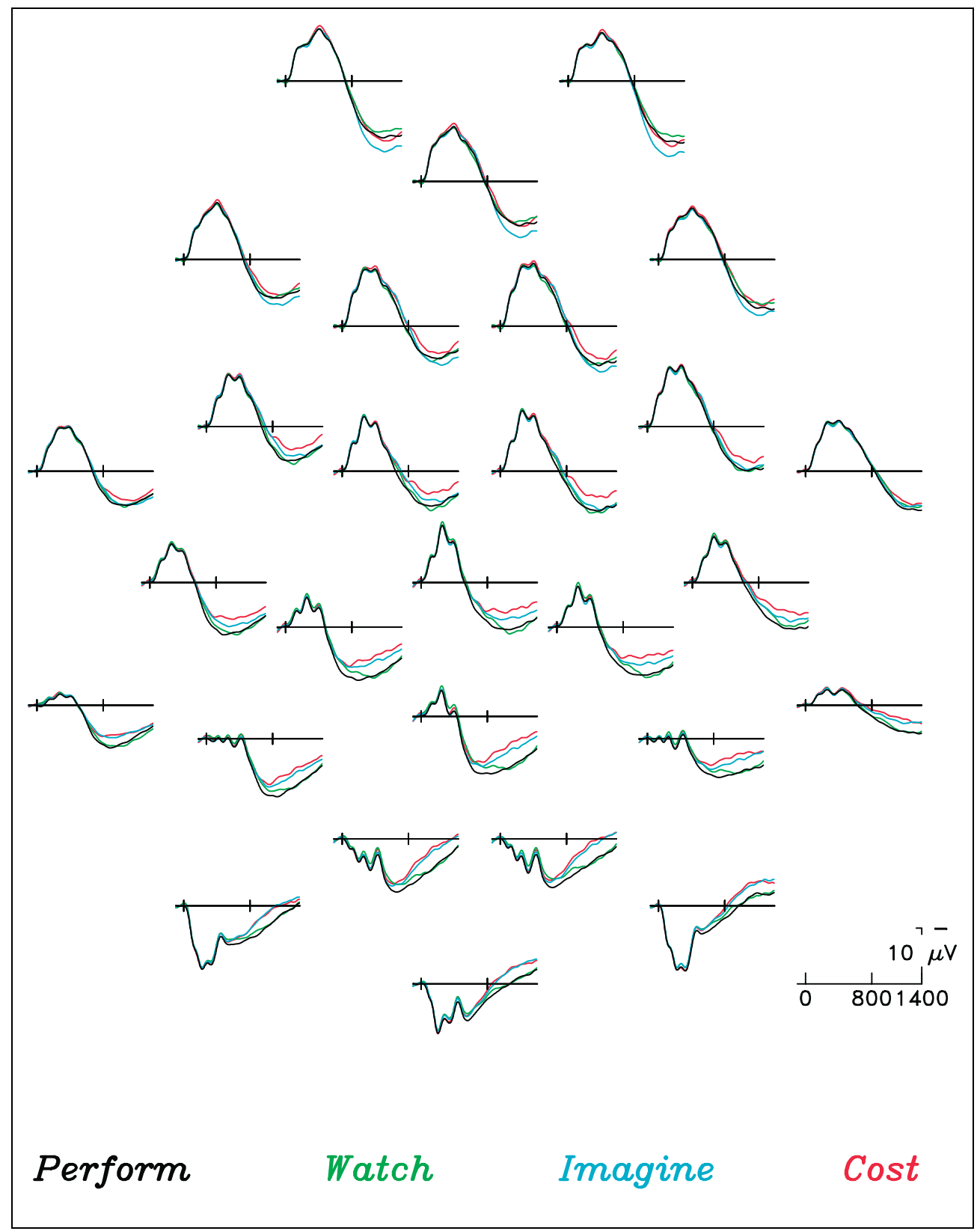

in 200-msec latency windows, beginning at $600 \mathrm{msec}$ and ending at 1,400 msec poststimulus onset, all relative to the 100-msec prestimulus baseline (Tables 3-6). ANOVAs are used to compare conditions pairwise, separately for three lateral chains of electrode sites defined by their distance from the midline (medial vs. dorsal vs. lateral, MDL). Each analysis uses repeated measures factors of Task, Anterior-to-Posterior scalp location (AP, four levels), and Hemisphere (right vs. left), together with subjects (16) as the random factor. Results involving the third ANOVA factor of hemisphere (right vs. left) are discussed in the section titled "Influences of encoding hand." Below, we first summarize the pattern of results, then address how much support they lend to specific hypotheses about the similarities and differences among retrieval of the four sorts of encoding episodes.

\section{Preliminary Summary}

The most notable event between 600 and $800 \mathrm{msec}$ is the divergence of the Perform-encoded ERPs from those to all other conditions. Figure 2 shows that the largest positivity is in the Perform condition-most evident at posterior sites and largest over medial sites. Also between 600 and $800 \mathrm{msec}$, objects from the Watch condition are beginning to elicit slightly more positive ERPs than those in the Imagine or Cost conditions, yielding small but statistically significant differences between them (Table 3).

The results in the 800-1000-msec window show a complex pattern of results varying across the scalp that is quite distinct from the earlier latency window. Objects from the Imagine task elicit more positive ERPs than do 
Table 3. ANOVA Results From Two-Way Task Comparisons for Medial (M), Dorsal (D), and Lateral (L) Sites and Anterior/Posterior (AP) from 600 to 800 msec Poststimulus Onset

\begin{tabular}{|c|c|c|c|c|c|c|}
\hline & \multicolumn{3}{|c|}{ Main Effect of Task (Two Levels), F(1,15) } & \multicolumn{3}{|c|}{ Task (Two Levels) $\times$ AP (Four Levels), F(3,45) } \\
\hline & Watch & Imagine & Cost & Watch & Imagine & Cost \\
\hline \multicolumn{7}{|c|}{ Perform } \\
\hline M & $6.34 *$ & $14.1 * *$ & $10.6^{*}$ & $4.07^{*}, e=.44$ & $n s$ & ns \\
\hline $\mathrm{D}$ & ns & $13.7^{*}$ & 7.31 & $n s$ & $4.39, e=.58$ & $n s$ \\
\hline $\mathrm{L}$ & ns & $17.9 * *$ & 6.34 & $n s$ & ns & $n s$ \\
\hline \multicolumn{7}{|c|}{ Watch } \\
\hline M & - & ns & ns & - & $5.93^{*}, e=.52$ & $n s$ \\
\hline $\mathrm{D}$ & - & ns & 5.88 & - & ns & $n s$ \\
\hline $\mathrm{L}$ & - & ns & 4.9 & - & ns & $n s$ \\
\hline \multicolumn{7}{|c|}{ Imagine } \\
\hline M & - & - & $n s$ & - & - & $n s$ \\
\hline $\mathrm{D}$ & - & - & $n s$ & - & - & $n s$ \\
\hline $\mathrm{L}$ & - & - & $n s$ & - & - & $n s$ \\
\hline
\end{tabular}

$\mathrm{M}=$ medial $; \mathrm{D}=$ dorsal $\mathrm{L}=$ lateral to midline; $n s=$ nonsignificant; $e=$ Huhyn-Feldt correction for nonsphericity of variance used for tests with more than one degree of freedom in the numerator. All $F$ ratios shown are significant at $p \leq .05$.

*The $F$ ratio is significant at $p \leq .01$.

**The $F$ ratio is significant at $p \leq .001$.

Table 4. ANOVA Results From Two-Way Task Comparisons for Medial (M), Dorsal (D), and Lateral (L) Sites and Anterior/Posterior (AP) in 800-1000 msec Poststimulus Onset Time Window

\begin{tabular}{|c|c|c|c|c|c|c|}
\hline & \multicolumn{3}{|c|}{ Main Effect of Task (Two Levels), F(1,15) } & \multicolumn{3}{|c|}{ Task (Two Levels) $\times$ AP (Four Levels), F(3,45) } \\
\hline & Watch & Imagine & Cost & Watch & Imagine & Cost \\
\hline \multicolumn{7}{|c|}{ Perform } \\
\hline M & ns & $9.52 *$ & $17.3^{* *}$ & ns & 4.53 & ns \\
\hline $\mathrm{D}$ & ns & 4.31 & $15.0 * *$ & ns & $9.18^{* *}, e=.59$ & $7.06^{*}, e=.56$ \\
\hline $\mathrm{L}$ & 4.8 & $9.02 *$ & $19.5^{* *}$ & ns & $6.60, e=.44$ & $n s$ \\
\hline \multicolumn{7}{|c|}{ Watch } \\
\hline M & - & $4.15(.06)$ & $16.1 * *$ & - & $n s$ & $n s$ \\
\hline $\mathrm{D}$ & - & $n s$ & $15.5^{* *}$ & - & $8.90^{* *}, e=.51$ & $5.02, e=.49$ \\
\hline $\mathrm{L}$ & - & ns & $18.5^{* *}$ & - & $8.24^{*}, e=.41$ & ns \\
\hline \multicolumn{7}{|c|}{ Imagine } \\
\hline M & - & - & 6.20 & - & - & $n s$ \\
\hline $\mathrm{D}$ & - & - & $13.6^{*}$ & - & - & ns \\
\hline $\mathrm{L}$ & - & - & 7.8 & - & - & $4.37, e=.45$ \\
\hline
\end{tabular}

$\mathrm{M}=$ medial; $\mathrm{D}=$ dorsal; $\mathrm{L}=$ lateral to midline; $n s=$ nonsignificant; $e=$ Huhyn-Feldt correction for nonsphericity of variance used for tests with more than one degree of freedom in the numerator. All $F$ ratios shown are significant at $p \leq .05$.

*The $F$ ratio is significant at $p \leq .01$.

**The $F$ ratio is significant at $p \leq .001$. 
Table 5. ANOVA Results From Two-Way Task Comparisons for Medial (M), Dorsal (D), and Lateral (L) Sites and Anterior/Posterior (AP) in 1000-1200 msec Poststimulus Onset Time Window

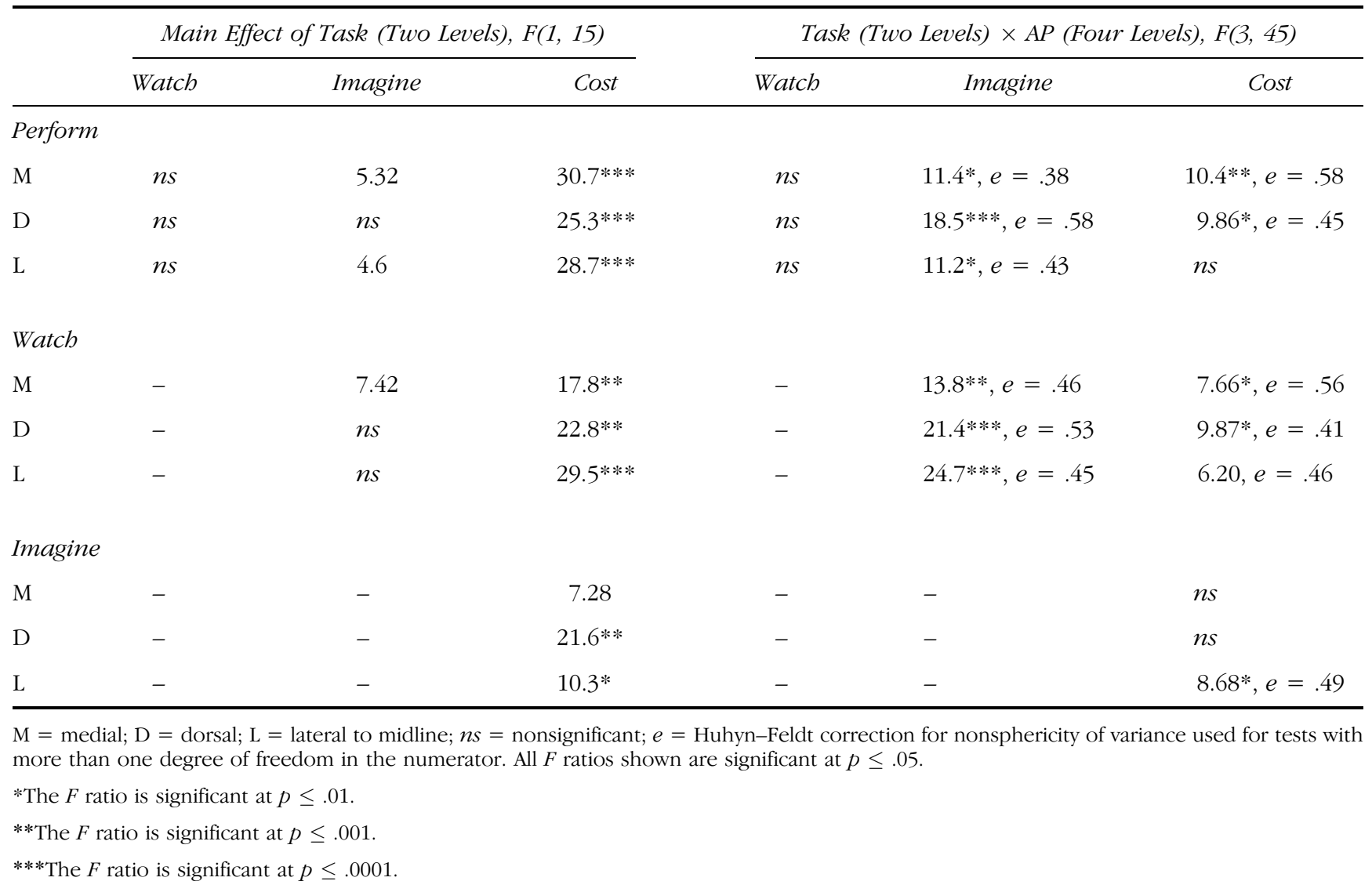

objects from the other three conditions, but only over prefrontal sites (Task $\times$ AP interactions in Table 4). At the same time, two additional and different patterns emerge. Over fronto-central sites, ERPs to objects from the Cost task are distinct from the three action conditions-Performed, Imagined, or Watched. Over the parietal, temporal, and occipital sites, the ERPs to objects from both the Perform and watch tasks are characterized by indistinguishable ERPs that are more positive than those in the Imagine and Cost tasks.

Between 1000 and $1400 \mathrm{msec}$ (Tables 5 and 6), the patterns that emerged in the previous time window stabilize: (1) at the prefrontal sites, the response to Imagine objects is distinct from all others (Figure 3, top); (2) at the frontal sites, the response to Cost objects stands apart from those for the three non-action conditions (Figure 3, middle); and (3) at the parietal, temporal, and occipital sites, responses to Perform and Watch objects pattern together as do those to imagine and Cost objects (Figure 3, bottom).

\section{Memory for Self-Generated Activities Versus External Events}

A "self versus other" division predicts a distinction between the brain's response to Watch trials (wherein participants observed the experimenter's actions) and responses from the other conditions with self-generated responses. However, at no point does the response to the Watch task stand apart from all others. The behavioral data showed that insofar as Watch trials are confused, it is with those imagined, so that source confusions also were not based on self-generation per se.

\section{Memory for Events With and Without Actions}

Another possible distinction based on the literature is between retrieval of memories involving action and those not involving action. According to this dichotomy, the brain's response during retrieval of objects from the three action tasks (Perform, Watch, Imagine) should be similar to each other and distinct from that to objects from the Cost task. The results provide partial confirmation for this hypothesis: over the frontal sites, ERPs to Perform, Watch, and Imagine trials are similar and distinct from the Cost trials (Figure 3, middle). Cost ERPs differ from the average of the other three conditions at the six frontal sites between 800 and $1000 \mathrm{msec}, 1000$ and $1200 \mathrm{msec}$, and 1200 and $1400 \mathrm{msec}, F(1,15)=11.3, p<.005,20.9, p<.0005$, 20.7, $p<.0005$, but not between 600 and $800 \mathrm{msec}$, $F(1,15)=2.51, p>.10$. 
Table 6. ANOVA Results From Two-Way Task Comparisons for Medial (M), Dorsal (D), and Lateral (L) Sites and Anterior/Posterior (AP) in 1200-1400 msec Poststimulus Onset Time Window

\begin{tabular}{|c|c|c|c|c|c|c|}
\hline & \multicolumn{3}{|c|}{ Main Effect of Task (Two Levels), F(1, 15) } & \multicolumn{3}{|c|}{ Task (Two Levels) $\times$ AP (Four Levels), F $(3,45)$} \\
\hline & Watch & Imagine & Cost & Watch & Imagine & Cost \\
\hline \multicolumn{7}{|c|}{ Perform } \\
\hline M & ns & $11.3 * *$ & $19.9 * *$ & $n s$ & $19.0 * *$ & $10.8 * *$ \\
\hline $\mathrm{D}$ & $n s$ & $n s$ & $12.8^{*}$ & $n s$ & $25.1 * * *, e=.77$ & $10.7^{*}, e=.41$ \\
\hline $\mathrm{L}$ & $n s$ & $4.2(0.06)$ & $15.0 * *$ & ns & $14.8^{* * *}, e=.53$ & $n s$ \\
\hline \multicolumn{7}{|c|}{ Watch } \\
\hline M & - & $n s$ & $11.8^{*}$ & - & $23.0^{* * *}, e=.50$ & $5.15^{*}, e=.53$ \\
\hline $\mathrm{D}$ & - & $n s$ & $10.6^{*}$ & - & $23.3^{* * *}, e=.55$ & $7.53^{*}, e=.40$ \\
\hline $\mathrm{L}$ & - & $n s$ & $16.3 * *$ & - & $32.3 * * *, e=.56$ & $n s$ \\
\hline \multicolumn{7}{|c|}{ Imagine } \\
\hline M & - & - & $10.1^{*}$ & - & - & $7.12 *, e=.53$ \\
\hline $\mathrm{D}$ & - & - & $19.8 * *$ & - & - & $n s$ \\
\hline $\mathrm{L}$ & - & - & 5.62 & - & - & $5.86, e=.44$ \\
\hline
\end{tabular}

\section{Memory for Events With and Without Visual Motion}

Although the Perform, Imagine, and Watch tasks all involve actions, only the Perform and Watch tasks involve actual movement. The results provide clear support for a motion/nonmotion distinction over posterior scalp sites (Figure 3, bottom): the ERPs to Perform and Watch objects are statistically indistinguishable from each other between 1000 and $1400 \mathrm{msec}$ poststimulus onset, but do differ from the ERPs to Imagine and Cost objects. A follow up ANOVA test on the posterior temporal, parietal, and occipital sites confirm this division between 1000 and $1400 \mathrm{msec}$ [Perform and Watch vs. Imagine and Cost, $F(1,15)=39.81$, $p<.0001]$. Imagine and Cost do not differ at these sites, $F(1,15)<1.5$.

\section{Memory for Self-Performed Actions}

Although some prior research suggests overlap among the three action encoding tasks, only the Perform encoding task involves execution of a motor plan, visuomotor coordination between object and hand, and kinesthetic feedback from executing a movement. Over the posterior half of the head, ERPs elicited by perform-encoded objects differed from the other three conditions in being more positive. This separation of perform from the other conditions is short-lived (between 600 and $800 \mathrm{msec}$ ); a few hundred milliseconds later, the Perform and Watch conditions elicit identical ERPs. However, it is likely that the overall better memory for objects from the perform condition is due to executing the motor plan, visuomotor coordination of the object, along with kinesthetic feedback from action execution.

\section{Influences of Encoding Hand}

Comparisons among the conditions with and without actions during initial encoding offer some support for the hypothesis that brain activity during successful retrieval of source reflects this distinction, at least over the frontal scalp sites. However, the motor recapitulation hypothesis also predicts hemispheric differences as a function of hand used to perform the action. Depending on how specific motor imagery is, laterality differences may also be expected during the recall of imagined actions. Finally, if observing a unimanual action also engages contralateral motor association cortex, the Watch condition also may elicit asymmetric brain activity as a function of which hand the experimenter used to manipulate the objects. 
Figure 3. (Top) Grand average ERPs from right and left dorsal prefrontal scalp sites elicited by correctly remembered objects encoded with Perform, Watch, Imagine, and Cost tasks. (Middle) Grand average ERPs from the right and left medial frontocentral scalp sites elicited by correctly remembered objects encoded with Perform, Watch, Imagine, and Cost tasks. (Bottom) Grand average ERPs from the left lateral temporal, parietal, and occipital scalp sites elicited by correctly remembered objects encoded with Perform, Watch, Imagine, and Cost tasks.

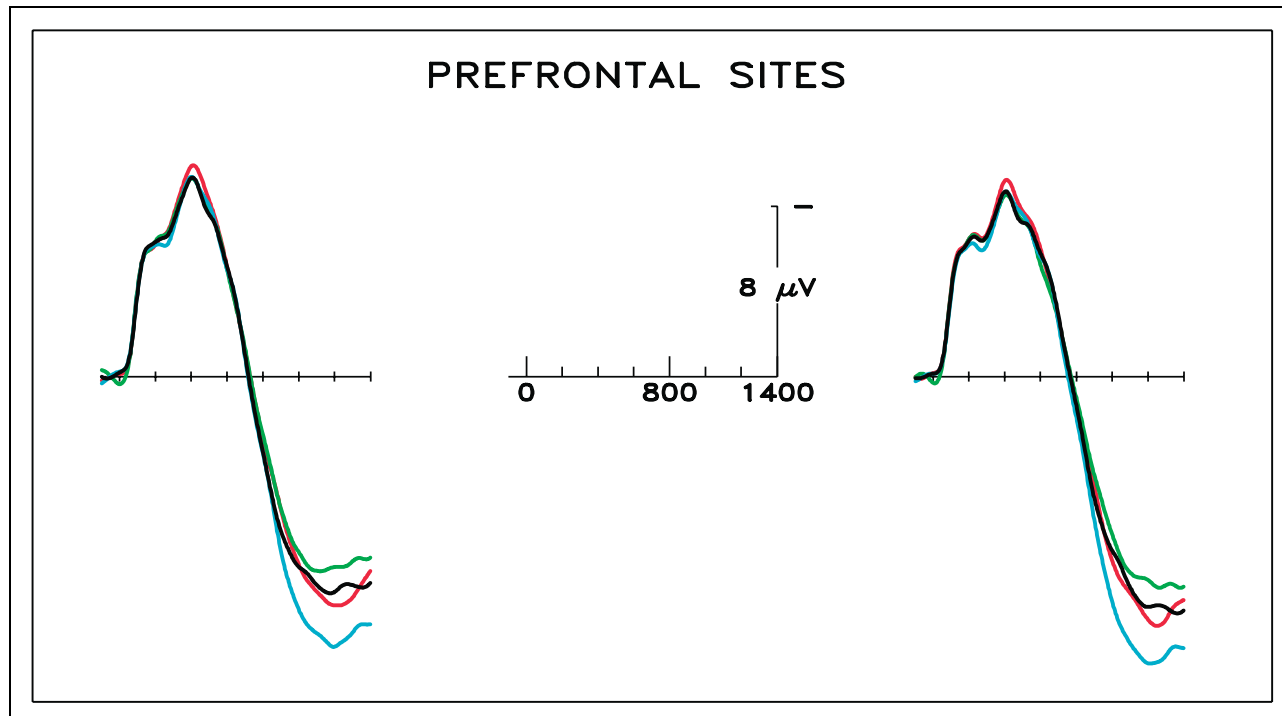

FRONTAL SITES
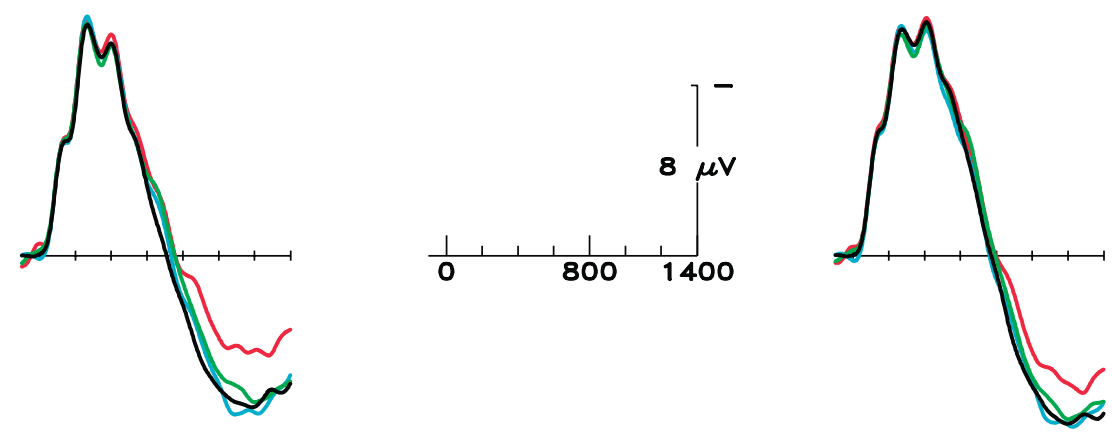

POSTERIOR SITES
Temporal

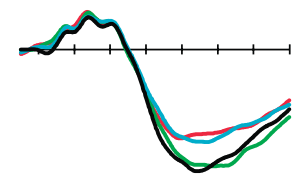

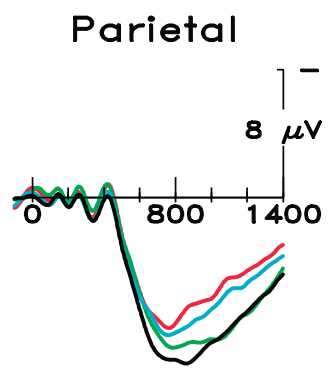

Occipital

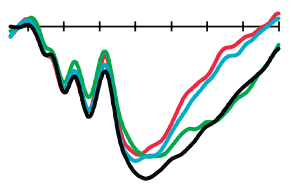

Watch
Hemispheric differences independent of encoding hand. Figure 4 shows that, collapsed across encoding hand, all four conditions elicited laterally asymmetric ERPs, with the nature of left/right difference varying along the AP axis. At prefrontal and frontal sites, ERPs are more positive over the right than left hemisphere, starting at $\sim 900 \mathrm{msec}$ poststimulus. By hemisphere contrast, at central, parietal, temporal, and occipital sites, ERPs are more positive over the left than the right from $\sim 400 \mathrm{msec}$ throughout the epoch. Both asymmetries are strongest at dorsal and lateral sites, so that ANOVAs including all four tasks yielded interactions between 
Figure 4. Grand average ERPs elicited over the right and left hemispheres to correctly remembered objects encoded with Perform, Watch, Imagine, and Cost tasks at the midline sites.

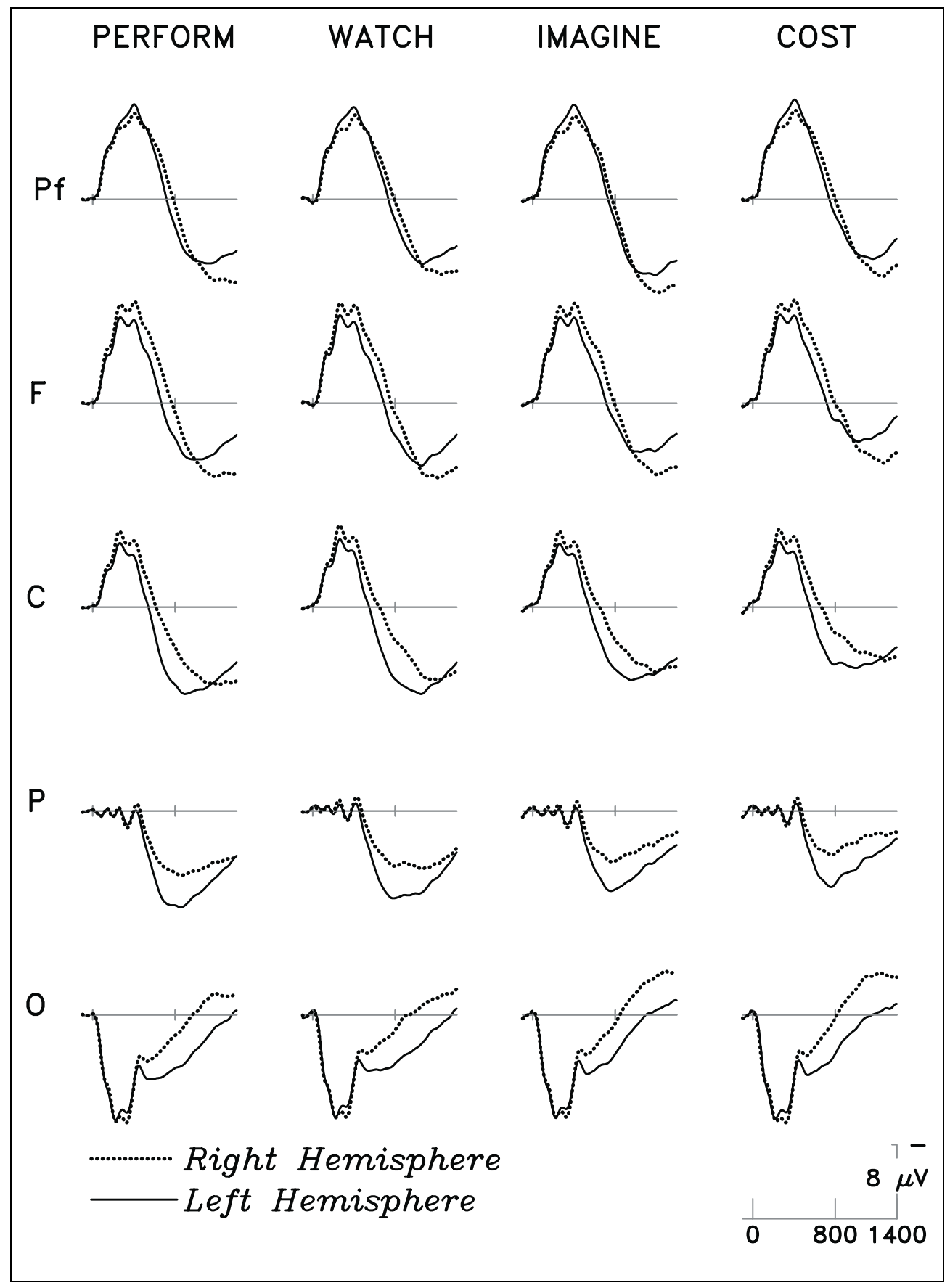

the hemisphere factor and the MDL factor in the 600-800-, 800-1000-, and 1000-1200-msec windows, $F^{\prime} \mathrm{s}(2,30)=21.5,34.4$, and 12.0, respectively, $e$ 's $=$ 1.00 , all $p$ 's $<.0001$. The differential asymmetries over anterior and posterior regions yielded interactions of Hemisphere $\times$ AP by MDL in all measurement windows, $F^{\prime}$ 's $(6,90)>3.55$, $e$ 's $>.75, p$ 's $<.01$. However, there is no difference in this overall pattern of asymmetries as a function of encoding task.

Main effect of encoding hand. Data from each encoding task were quantified as mean amplitude measures from 600 to $1,400 \mathrm{msec}$ poststimulus onset, and subjected to ANOVAs with factors of Encoding Hand (right, left) and Hemisphere (right, left). Table 7 and Figure 5 present the main effects and Table 7 and Figure 6 the interactions for these analyses. A robust finding is the significant main effect of action hand: objects encoded with right hand involvement elicit more positive ERPs than do objects encoded with the left hand (Table 7 , Figure 5). Table 7 also shows a main effect of encoding hand over the prefrontal and frontal sites during retrieval of both Perform- and Watch-encoded items, and a trend for effects over frontal, central-parietal, and occipital sites for imagine-encoded objects. An influence of encoding hand during source retrieval, or a band tag, is apparent for each of the three action tasks, but not for 
Table 7. ANOVA Results With Factors of Encoding Hand and Hemisphere, for Medial Prefrontal, Frontal, Central/Parietal, and Occipital Sites in 600-1400 msec Poststimulus Onset Time Window

\begin{tabular}{|c|c|c|}
\hline & $\begin{array}{l}\text { Main Effect of } \\
\text { Hand, } F(1,15)\end{array}$ & $\begin{array}{c}\text { Hand } \times \text { Hemisphere }, \\
F(1,15)\end{array}$ \\
\hline \multicolumn{3}{|l|}{ Perform } \\
\hline Prefrontal & $8.94^{*}$ & 2.82 \\
\hline Frontal & $7.66^{*}$ & $<1.0$ \\
\hline Central-Parietal & $3.05, p<.10$ & $<1.0$ \\
\hline Occipital & $<1.0$ & $<1.5$ \\
\hline \multicolumn{3}{|l|}{ Watch } \\
\hline Prefrontal & $2.57, p=.12$ & $3.18, p<.10$ \\
\hline Frontal & $2.54, p=.13$ & $3.57, p<.10$ \\
\hline Central-Parietal & $2.74, p=.11$ & $<1.5$ \\
\hline Occipital & $<1.0$ & $<1.0$ \\
\hline \multicolumn{3}{|l|}{ Imagine } \\
\hline Prefrontal & $<1.75$ & $<1.0$ \\
\hline Frontal & $11.2^{*}$ & $<1.0$ \\
\hline Central-Parietal & $16.7 * *$ & $<1.0$ \\
\hline Occipital & 6.86 & $3.18, p<.10$ \\
\hline \multicolumn{3}{|l|}{ Cost } \\
\hline Prefrontal & $<1.0$ & $<1.0$ \\
\hline Frontal & $<1.0$ & $<1.0$ \\
\hline Central-Parietal & $<1.0$ & $<2.5$ \\
\hline Occipital & $<1.0$ & $<1.0$ \\
\hline
\end{tabular}

the cost task. For the cost condition, "encoding hand" serves as a control variable coding the location of the object to either the left or right of the participant during the study.

Interaction effect of encoding hand and hemisphere. The motor recapitulation hypothesis predicts a Hand $x$ Hemisphere interaction, in that whatever pattern is observed for the right hand encodings, the reverse pattern should be observed for the left hand encodings. The predicted interaction can be seen at prefrontal sites for the Perform and Watch conditions, and at the frontal sites for the Watch condition. No such contralateral/ ipsilateral patterns of ERP activity are present in the Imagine condition. As can be seen in Figure 5, the Hemisphere $\times$ Hand interactions above are based on small amplitude differences. Again the Cost condition, "encoding hand" serves as a control variable indicating that the hemispheric patterns did not interact with object location.

\section{DISCUSSION}

This experiment was aimed at determining whether qualitatively different experiences during the initial encoding of an object would be reflected in qualitatively different brain activity as participants, faced with the object, attempt to recall the nature of that experience. We found this to be the case.

\section{Actions: Performed, Watched, and Imagined}

Based on the motor imagery and action perception literatures, we predicted that successful retrieval of episodes involving action would elicit similar ERPs especially over the motor, premotor, and perhaps the parietal cortical areas, ${ }^{1}$ compared to cost-encoded objects with no motor component. And, the three action memory conditions did elicit very similar ERPs at the fronto-central scalp sites (approximately over premotor cortex), although not at parietal sites, that clearly differ from ERPs in the non-action cost condition. Although some PET studies find parietal activations for motor performance and motor imagery (Rizzolatti et al., 1996; Stephan et al., 1995), at least one suggests parietal activations reflect analysis of an object's spatial properties for identification (required by all encoding tasks) and not motor involvement (Faillenot, Toni, Decety, Gregoire, \& Jeannerod, 1997).

Other scalp sites revealed differences among the three types of action tasks consistent with the participants'

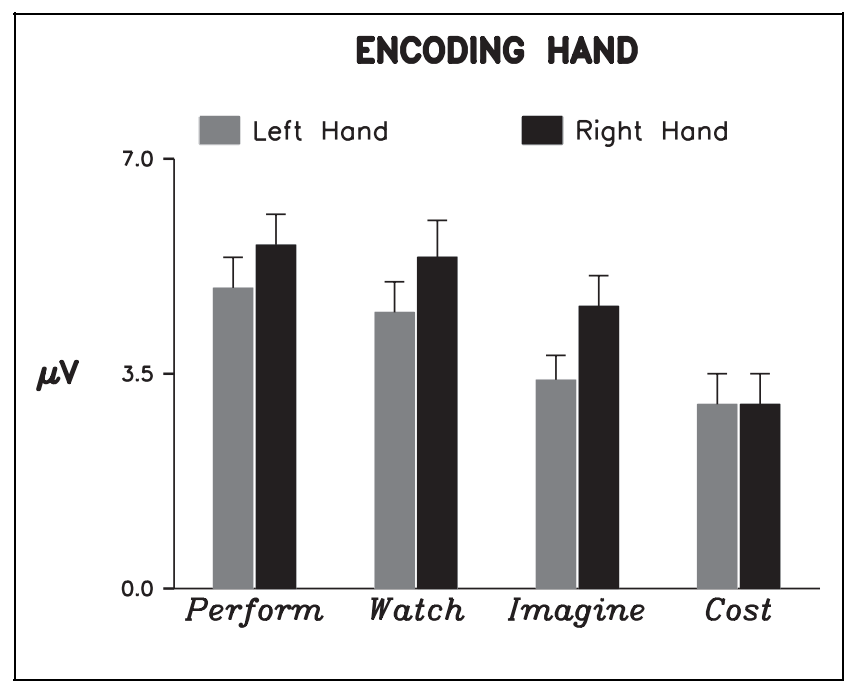

Figure 5. Correct encoding task judgments are shown here sorted by encoding hand at study. Mean amplitude measures from 600 to 1400 msec poststimulus onset at the medial sites from the left and right encoding hand. 
Figure 6. The interaction of encoding hand and hemisphere are shown here. Mean amplitude measures from 600 to $1400 \mathrm{msec}$ poststimulus onset at medial sites from left and right hemispheres are displayed.

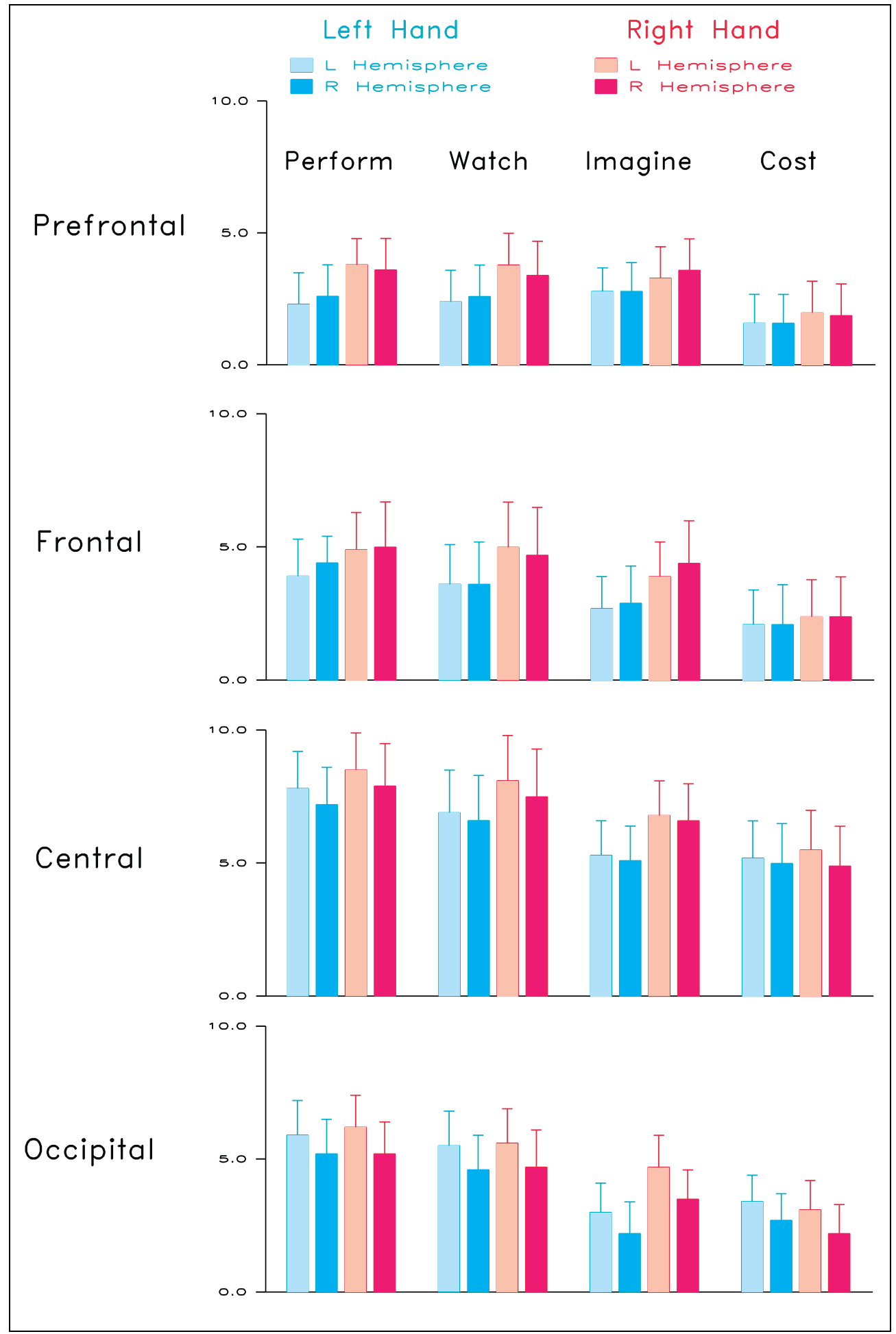

success in distinguishing sources, and may explain why various action tasks did not prove particularly confusable during recall; indeed, action-encoded objects were generally more memorable than the cost-encoded objects. Only Perform and Watch trials involve the presence of overt actions or moving objects, and the ERPs to these two conditions are clearly distinct from those to the Imagine and Cost conditions at sites (parietal, posterior temporal, and occipital) that we would expect to be most sensitive to visual memory attributes. In fact, Perform and Watch conditions only differ quantitatively: perform-encoded objects elicit more accurate judgments, faster reaction times, and more positive ERPs between 600 and $800 \mathrm{msec}$ poststimulus onset but are otherwise similar in wave shape and scalp distribution. This qualitative similarity of the Perform and Watch ERPs 
is perhaps surprising in light of studies indicating that brain-damaged patients' memories derive a benefit from self-performed actions relative to other types of encoding. McAndrews and Milner (1991), for example, found that patients with left and right frontal damage were impaired in recency judgments for objects encoded with a naming task, but this group difference was ameliorated for objects encoded with the perform task. Butters, Kaszniak, Glisky, and Eslinger (1994) extended this finding to several additional encoding tasks including watch, imagine, and frequency of object use in everyday life. Specifically, normal controls' recency judgments were equivalent across all encoding tasks whereas frontal patients showed depressed performance in all but the perform task. If this advantage reflects some qualitative difference between the memory traces formed during performance versus other encodings, then this should appear in qualitatively different pattern of ERPs to Perform-encoded objects. This was not the case. We see only quantitative differences between Perform- and Watch-encoded objects: greater accuracy and earlier ERP positivity for Perform. Perhaps the memory benefit from perform encoding in frontal patients is similarly quantitative in nature, though these previous studies also differ from ours in assessing recency (rather than source) judgments in much older participants.

\section{Recapitulation of Motor Encoding}

Although participants were not asked to indicate which hand they (or the experimenter) had used during any of the action-encoding tasks, source memory tests may naturally elicit retrieval of such episodic information. A strong version of the hypothesis that retrieval recapitulates encoding would predict a laterally asymmetric pattern of ERPs over the two hemispheres at test as a function of hand used and perhaps watched during study, and there is some evidence of this for Perform and Watch objects. Although ERPs possess sufficient spatial resolution to yield robust hemispheric asymmetries during and immediately prior to active limb movements reflecting engagement of the motor cortex (e.g., Knosche, Praamstra, Stegeman, \& Peters, 1996; Kutas \& Donchin, 1980), they may be less able to distinguish left and right cortical regions close to the midline (such as the supplementary motor areas). Also, motor recapitulation and source retrieval processes may co-occur such that the late positive component associated with source retrieval may overwhelm the smaller, and perhaps less temporally synchronized activity associated with motor recapitulation. We are currently testing the motor recapitulation hypothesis with hemodynamic brain imaging methods given their better spatial resolution (Senkfor \& Gabrieli, in preparation).

A more robust and unexpected finding is that images of objects originally manipulated with the right hand elicited more positive ERPs than those manipulated with the left hand over both hemispheres for all three action tasks. The absence of this right/left "hand tag" ERP for Cost-encoded objects indicates that it is not due to the lateral spatial location of the objects during study, as Cost objects also were placed either to the left or right of the participant. This right/left difference also cannot reflect retrieval of egocentric information about object location during the study phase, as it was in the same direction for Perform and Watch encoding although an object on the right was handled with the participant's right hand during Perform and the experimenter's left hand during Watch. Perhaps the objects manipulated with the dominant hand (all participants were righthanded) are simply more memorable. However, there were no accuracy or reaction time benefits for "righthand" objects as opposed to left, and the scalp distribution of the encoding hand effects in the Perform, Watch, and Imagine conditions did differ. In sum, we speculate that the impact of encoding hand is in part driven by participants' handedness, albeit in subtly different ways for each action task depending on the fluency of the manipulation (see Maruff et al., 1999). Whether or not the influence of encoding hand, independent of hemisphere, implies that motor information is retrieved, it does suggest that very specific markers are embedded within an encoding episode-including a "hand tag" —and are recovered at test.

\section{Memory for Self- Versus Other-Generated Events}

Self-reference has been considered a critical attribute of episodic memory since Tulving (1972) first suggested that episodic memory should be separated from semantic memory (general knowledge). Self-reference and self-generation both yield robust beneficial effects on memory. Numerous experiments with word lists show that deciding how well a word applies to oneself yields recognition superior to semantic study tasks (Rogers, Kuiper, \& Kirker, 1977). In word list studies, items that one generates oneself are better remembered than words merely read (Slamecka \& Graf, 1978). More recently, contrasts between autobiographical and public events have been the topic of hemodynamic imaging studies, with results suggesting that retrieval of personal memories may recruit different brain regions than retrieval of impersonal memories (Maguire \& Mummery, 1999; Fink et al., 1996). Among other findings, the variety and robustness of phenomenon implicating personal involvement as an important factor in memory encoding and/or retrieval has led to the suggestion that one's "self" is a mental structure that plays a central role in a great deal of cognitive processing (Kihlstrom \& Klein, 1994; Kihlstrom, 1995).

However, the exact nature of the relationship between "self" and memory is unclear. For instance, it has been reported that judging how well a word applies to a family member is as good an encoding task as 
judging self-referentiality (Bower \& Gilligan, 1979), suggesting that this effect may have more to do with general depth of processing or elaboration than self-reference per se (Symons \& Johnson, 1997). The self-generation effect may similarly be due to the joint action of several processes: personal involvement may lead to memories that are more affect-laden (Eich, 1995) or that contain some residue of one's own cognitive operations during the original event (Johnson, Raye, Foley, \& Foley, 1981). When a source memory judgement is required, it is possible that self-involvement is inferred from multiple aspects of the recovered content, rather than directly retrieved as a unitary feature.

The current results lend little support to a strict dichotomy between self- and other-generated episodes in memory, nor do they suggest that self-generation always yields the best memory. In the accuracy data, the "other" encoding task (watching the experimenter perform an action) yielded the second-best performance rather than the worst. In the source confusion matrix, the most prevalent error was judging cost-encoded items as imagined (two self-generation tests), but the second-most likely confusion crossed the self/other boundary (imagine-encoded items judged as watched). In the ERP data, retrieval of a self-generated overt action (Perform) and an other-generated overt action (Watch) yielded the most similar brain activity. Overall, the pattern of ERPs associated with correct source memory judgements varied with the specific attributes of the encoded episodes: retrieval of action events (performed, watched, or imagined) elicited similar ERPs over the premotor cortex, while retrieval of events including moving hands and objects elicited similar ERPs at the posterior sites over the visual cortex. The results are most consistent with the idea that "self versus other" is not a fundamental event attribute stored in memory, but rather a complex inference computed from more elementary attributes encoded during the original event.

\section{Motor Imagery Versus Other Encoding Tasks}

ERPs for Imagine objects can be differentiated from those to all other conditions at the prefrontal sites. The larger positivity to Imagine objects began $900 \mathrm{msec}$ poststimulus onset, well after activity at more posterior sites begins to distinguish accurate from inaccurate responses and to differentiate the four encoding tasks. In previous studies, we have observed large prefrontal positivities when participants are asked to make source memory judgments as compared to yes/no recognition judgements (Van Petten et al., 2000; Senkfor \& Van Petten, 1998; Senkfor et al., submitted). This prefrontal effect has been similar across content domains and for correct and incorrect source judgments, suggesting that it indexes retrieval mode rather than memory content or retrieval success. The Perform, Watch, and Cost conditions accord well with our previous finding that only non-prefrontal ERPs are sensitive to retrieval success (Figure 1) or retrieval content (Figures 2 and 3). However, it is difficult to offer an account for the prefrontal positivity in the Imagine condition in terms of retrieval mode given that all the objects called for source judgements.

What about sheer retrieval effort? Cognitive effort is a subjective variable that cannot be measured directly, but is usually inferred from behavioral data. The performance data indicated that accuracy in the Imagine condition was slightly better than the cost condition, but that RT was slowest of the four conditions, suggesting that it may indeed have been the hardest condition. The impact of source retrieval difficulty on prefrontal brain activity deserves further attention. However, a straightforward "effort" interpretation of the prefrontal positivity for the imagine conditions would seem to predict some gradient of this effect across the four conditions, as substantial differences in accuracy and RT were observed between other conditions (e.g., Perform and Cost). This was not observed.

It is thus possible that, like the ERPs at other scalp sites, the prefrontal positivity during retrieval of imagined actions has some relationship to the brain regions engaged during the initial study phase. This interpretation would suggest that prefrontal areas have a greater role in motor imagery than performance or observation. The few hemodynamic imaging studies including these comparisons suggest that imagining an action is associated with greater blood flow in the prefrontal cortex, although different studies implicate different prefrontal regions (Grafton et al., 1996; Stephan et al., 1995; Ingvar \& Philipsson, 1977). Indeed, Frith and Dolan (1996) argue that "frontal activity is a critical component of motor imagery ... because in order to imagine something we have to "hold it in mind"' (p. 177). They postulated a similarity between imagined action and other working memory tasks known to engage the prefrontal cortex. It is also possible that motor imagery, as compared to execution, involves an active inhibitory process that prevents the imagined action from being carried out. In any case, our finding that merely remembering an imagined action is correlated with brain electrical activity over the prefrontal cortex is a novel and unexpected finding.

\section{Conclusions}

In sum, we find that patterns of brain electrical activity systematically vary with the content of the information to be retrieved. Moreover, we find these content specific effects in response to physically identical stimulus materials that vary only in the nature of the episodic memories they trigger. This finding of content specificity is thus unlike reports of material specificity in which different sorts of stimuli (words, pictures, textures) are compared (e.g., Wagner et al., 1998; Fletcher, Shallice, 
Frith, Frackowiak, \& Dolan, 1996; but also see Kohler, Moscovitch, Winocur, Houle, \& McIntosh, 1998; Nyberg, 1996, for a similar design with PET).

Specifically we find that during retrieval: (1) episodes involving actions elicit similar ERPs over the premotor cortex (frontal sites) that are distinct from those to the non-action Cost estimation task; (2) episodes with and without overt actions are clearly distinguishable at parietal, posterior temporal, and occipital sites; and (3) memory for imagined movements elicit a larger prefrontal positivity than memory for executed actions, observed actions, or cost estimation. These patterns of brain activity during retrieval can be seen as in large part isomorphic with processes (and associated brain areas) engaged during initial study: motor association cortex during action tasks, visual processing of movement (hands and objects) during overt actions, and prefrontal cortex during motor imagery. The one puzzling exception is the absence of a distinctive signature during retrieval of self-performed actions although this is the only encoding task that required active movement by the participant. Perform encoding yields the most accurate source memory and the associated ERPs are the first to diverge from those of the other conditions, and yet these ERPs are not qualitatively different from those to Watch-encoded objects. At test, Perform and Watch ERPs are likewise similar in differentiating objects initially manipulated with one versus the other hand ("hand tag"), suggesting equivalent treatments of the right and left hands regardless of whether it is the participants or the experimenters. Perhaps the limited spatial resolution of our measure or brain regions outside our recording range (e.g., cerebellum) precludes observation of an ERP signature of self-generated movement; this remains to be resolved.

\section{METHODS}

\section{Participants}

Eight men and eight women (18-30 years, mean $=20$ ), all right-handed (Oldfield, 1971) with only right-handed family members, normal or corrected-to-normal vision, normal color perception, and no reported history of neurological disorder were paid for their participation.

\section{Stimuli}

The participants were presented with 444 familiar objects (e.g., fork) or toy versions thereof (e.g., lawnmower) during study phases. All objects were photographed in color and digitized via a HewlettPackard 4c Scanner and presented as digital color images against a black background during the recognition test. The images subtended $6^{\circ}$ of visual angle horizontally and $8^{\circ}$ vertically.

\section{Procedure}

The experiment was conducted across two sessions, consisting of one study/test cycle, lasting $\sim 3.5 \mathrm{hr}$ each. During each study phase participants were exposed to 216 objects placed one at a time by the experimenter on a table to either to the left or right of the participant. As each object was presented, participants heard one of four randomly intermixed prerecorded encoding task instructions: take the next $7 \mathrm{sec}$ to (a) generate and Perform a common action with the object, (b) generate and Imagine a common action with the object, (c) Watch the experimenter perform a common action, or (d) generate and verbalize a realistic estimate of the object's cost. Half the objects were presented to the left of the participant and half to the right, with side indicating which hand was to handle the object (or to be imagined handling the object). After $7 \mathrm{sec}$, a tone signaled the object's removal by the experimenter; a new object was presented 4 sec later.

In the Perform condition, participants were asked to select a "typical" action for the object using only materials present (i.e., not to pantomime activities with materials not present), and to perform the action with the designated hand. If they could not think of an action quickly, participants were instructed to pick up and inspect the object ( $\sim 1 \%$ of the trials); it was the only condition wherein they touched the object. Instructions were identical for the Imagine task with the exception that participants were to imagine performing the action with the cued hand as vividly as possible. On Watch trials, the experimenter performed a typical action with the object with the cued hand. In the Cost task, participants gave a verbal estimate of how much it would cost to buy the object. Study sessions were videotaped for later review. Trials with atypical actions, where the wrong encoding task was carried out, the wrong hand was used, or the act/estimate was not given within the allotted time ( $\sim 1 \%$ of trials) were dropped from further analyses.

In each session, the recognition test included digital images (photographic quality) of all the studied objects (no new objects). Object images were presented for 300 msec with an interstimulus interval of 5,000 msec as participants made one of four responses ("Perform," "Imagine," "Watch," "Cost') to each on two keypads, using the index and second fingers of each hand. Participants were encouraged to balance speed and accuracy. Participants received a practice set of 12 objects before the study phase and a practice source recognition test with digital object images before the experimental test list presentation.

Eight different stimulus lists were constructed from the 432 items to counterbalance the four encoding tasks, encoding hand (right/left), and object sessions across subjects; the mapping of responses to the four fingers was counterbalanced within subjects. 


\section{Electrophysiological Methods}

EEG was recorded from tin electrodes in a commercially available cap with a geodesic array of 26 equidistant electrodes (for comparison to 10-20 system, see Ganis, Kutas, \& Sereno, 1996). Two additional prefrontal sites were placed above the nasion by $5 \%$ of the nasion to inion distance and $10 \%$ of the interaural distance laterally. An additional electrode was placed over the right mastoid. Horizontal eye movements were monitored via a right to left bipolar montage at the external canthi of the two eyes. Vertical eye movements and blinks were monitored via electrodes placed below the right and left eyes. Scalp sites and vertical eye electrodes were referenced to the left mastoid during recording, and rereferenced off-line to the average of the activity at left and right mastoids. EEG was amplified with a Grass Model 12 polygraph with half amplitude cutoffs of 0.01 and $100 \mathrm{~Hz}$, digitized on-line at a sampling rate of $250 \mathrm{~Hz}$. Trials with artifacts due to eye movement or amplifier saturation were rejected prior to averaging.

\section{Acknowledgments}

Funding was provided by the National Institute of Aging (AG14792, AG08313) and the National Institute of Mental Health (MH52893).

Reprint requests should be sent to Ava J. Senkfor, MGH-NMR Center, Massachusetts General Hospital, Harvard Medical School, 149 (2301) 13th Street, Charlestown, MA 02129-2000, USA or via e-mail: senkfor@nmr.mgh.harvard.edu.

\section{Note}

1. Whole movement-related potentials are maximal over the scalp as expected based on the known layout of the motor system, largest over the central brain areas.

\section{REFERENCES}

Backman, L. (1985). Further evidence for the lack of adult age differences on free recall of subject-performed tasks: The importance of motor action. Human Learning, 4, 79-87.

Binkofski, F., Amunts, K., Stephan, K. M., Posse, S., Schormann, T., Freund, H. J., Zilles, K., \& Seitz, R. J. (2000). Broca's area subserves imagery of motion: A combined cytoarchitectonic and fMRI study. Human Brain Mapping, 11, 273-285.

Beisteiner, R., Hollinger, P., Lindinger, G., Lang, W., \& Berthoz, A. (1995). Mental representations of movements: Brain potentials associated with imagination of hand movements. Electroencephalography and Clinical Neurophysiology, 96, 183-193.

Bower, G. H., \& Gilligan, S. G. (1979). Remembering information related to one's self. Journal of Research in Personality, 13, 420-432.

Brown, M. B. (1988). Log linear models. In W. J. Dixon (Ed.), BMDP statistical software manual (pp. 229-274). Berkeley University of California Press.

Butters, M. A., Kaszniak, A. W., Glisky, E. L., Eslinger, P. J., \& Schacter, D. L. (1994). Recency discrimination deficits in frontal lobe patients. Neuropsychology, 8, 343-353.
Cohen, G., \& Faulkner, D. (1989). Age differences in source forgetting: Effects on reality monitoring and eyewitness testimony. Psychology and Aging, 4, 10-17.

Cunnington, R., Iansek, R., Gradshaw, J. L., \& Phillips, J. G. (1996). Movement-related potentials associated with movement preparation and motor imagery. Experimental Brain Research, 111, 429-436.

Di Pelligrino, G., Fadiga, L., Fogassi, L., Gallese, V., \& Rizzolatti, G. (1992). Understanding motor events: A neurophysiological study. Experimental Brain Research, 91, 176-180.

Eich, E. (1995). Searching for mood dependent memory. Psychological Science, 6, 67-75.

Engelkamp, J., \& Zimmer, H. D. (1985). Attempt to distinguish between kinematic and motor memory components. Acta Psychologica, 58, 81-106.

Faillenot, I., Toni, I., Decety, J., Gregoire, M.-C., \& Jeannerod, M. (1997). Visual pathways for object-oriented action and object recognition: Functional anatomy with PET. Cerebral Cortex, 7, 77-85.

Fink, G. R., Markowitsch, H. J., Reinkemeier, M., Bruckbauer, T., Kessler, J., \& Heiss, W.-D. (1996). Cerebral representation of one's own past: Neural networks involved in autobiographical memory. Journal of Neuroscience, 16, 4275-4282.

Fletcher, P. C., Shallice, T., Frith, C. D., Frackowiak, R. S., \& Dolan, R. J. (1996). Brain activity during memory retrieval. The influence of imagery and semantic cueing. Brain, 119, 1587-1596.

Friedman, D. (1990). Endogenous brain potentials during continuous recognition for words. Biological Psychology, 30, 61-87.

Frith, C., \& Dolan, R. (1996). The role of the prefrontal cortex in higher cognitive functions. Cognitive Brain Research, 5, 175-181.

Ganis, G., Kutas, M., \& Sereno, M. (1996). The search for "common sense": An electrophysiological study of the comprehension of words and pictures in reading. Journal of Cognitive Neuroscience, 8, 89-106.

Glisky, E. L., Polster, M. R., \& Rothieaux, B. C. (1995). Double dissociation between item and source memory. Neuropsychology, 9, 229-235.

Grafton, S. T., Arbib, M. A, Fadiga, L., \& Rizzolatti, G. (1996). Localization of grasp representations in humans by positron emission tomography: 2. Observation compared with imagination. Experimental Brain Research, 112, 103-111.

Grezes, J., \& Decety, J. (2001). Functional anatomy of execution, mental simulation, observation, and verb generation of actions: A meta-analysis. Human Brain Mapping, 12, 1-19.

Hari, R., Forss, N., Avikainen, S., Kirveskari, E., Salenius, S., \& Rizzolatti, G. (1998). Activation of human primary motor cortex during action observation: A neuromagnetic study. Proceedings of the National Academy of Sciences, U.S.A., 95, 15061-15065.

Hashtroudi, S., Johnson, M. K., \& Chrosniak, L. D. (1989). Aging and source monitoring. Psychology and Aging, 4, 106-112.

Hashtroudi, S., Johnson, M. K., \& Chrosniak, L. D. (1990). Aging and qualitative characteristics of memories for perceived and imagined complex events. Psychology and Aging, 4, 106-112.

Heil, M., Rolke, B., Engelkamp, J., Roesler, F., Oezcan, M., \& Hennighausen, E. (1999). Event-related brain potentials during recognition of ordinary and bizarre action phrases following verbal and subject-performed encoding. European Journal of Cognitive Psychology, 11, 261-280.

Henkel, L. A., Johnson, M. K., \& De Leonardis, D. M. (1998). 
Aging and source monitoring: Cognitive processes and neuropsychological correlates. Journal of Experimental Psychology, General, 127, 251-268.

Ingvar, D. H., \& Philipsson, L. (1977). Distribution of cerebral blood flow in the dominant hemisphere during motor ideation and motor performance. Annals of Neurology, 2, 230-237.

Janowsky, J. S., Shimamura, A. P., Squire, \& L. R. (1989). Source memory impairment in patients with frontal lobe lesions. Neuropsychologia, 27, 1043-1056.

Johnson, M. K., Hashtroudi, S., \& Lindsay, S. D. (1993). Source memory. Psychological Bulletin, 114, 3-28.

Johnson, M. K., Kounios, J., \& Reeder, J. A. (1994). Time-course studies of reality monitoring. Psychological Bulletin, 114, 3-28.

Johnson, M. K., Raye, C. L., Foley, H. J., \& Foley, M. A. (1981). Cognitive operations and decision bias in reality monitoring. American Journal of Psychology, 94, 37-64.

Kihlstrom, J. F. (1995). Memory and consciousness: An appreciation of Claparède and Recognition et Moiitè. Consciousness and Cognition, 4, 379-386.

Kihlstrom, J. F., \& Klein, S. B. (1994). The self as a knowledge structure. In R. S. Wyer \& T. K. Srull (Eds.), Handbook of social cognition, vol. 1 (2nd ed., pp. 153-208). Hillsdale, NJ: Erlbaum.

Knosche, T., Praamstra, P., Stegeman, D., \& Peters, M. (1996). Linear estimation discriminates midline sources and a motor cortex contribution to the readiness potential. Electroencephalography and Clinical Neurophysiology, 99, 183-90.

Kohler, S., Moscovitch, M., Winocur, G., Houle, S., \& McIntosh, A. R. (1998). Networks of domain-specific and general regions involved in episodic memory for spatial location and object identity. Neuropsychologia, 36, 129-142.

Korda, M. (1997, 10/06/97). Prompting the president. New Yorker, 73, 88-95.

Kutas, M., \& Donchin, E. (1980). Preparation to respond as manifested by movement-related brain potentials. Brain Research, 202, 95-115.

Maguire, E. A., \& Mummery, C. J. (1999). Differential modulation of a common memory retrieval network revealed by positron emission tomography. Hippocampus, 9, 54-61.

Maruff, P., Wilson, P. H., De Fazio, J., Cerritelli, B., Hedt, A., \& Currie, J. (1999). Asymmetries between dominant and non-dominant hands in real and imagined motor task performance. Neuropsychologia, 37, 379-384.

McAndrews, M. P., \& Milner, B. (1991). The frontal cortex and memory for temporal order. Neuropsychologia, 29, 849-859.

Neville, H., Kutas, M., Chesney, G., \& Schmidt, A. L. (1986). Event-related brain potentials during initial encoding and recognition of congruous and incongruous words. Journal of Memory and Language, 25, 75-92.

Nyberg, L. (1996). General and specific brain regions involved in encoding and retrieval of events: What, where, and when. Proceedings of the National Academy of Sciences, U.S.A., 93, 11280-11285.

Oldfield, R. C. (1971). The assessment of handedness: The Edinburgh Inventory. Neuropsychologia, 9, 97-113.

Paller, K., \& Kutas, M. (1992). Brain potentials during memory retrieval provide neurophysiological support for the distinction between conscious recollection and priming Journal of Cognitive Neuroscience, 4, 375-391.

Rizzolatti, G., Fadiga, L., Gallese, V., \& Fogassi, L. (1996). Premotor cortex and the recognition of motor actions. Cognitive Brain Research, 3, 131-141.

Rogers, T. B., Kuiper, N. A., \& Kirker, W. S. (1977).
Self-reference and the encoding of personal information. Journal of Personality and Social Psychology, 35, 677-688.

Roland, R. E., Larsen, B., Lassen, N. A., \& Skinhoj, E. (1980). Supplementary motor area and other cortical areas in organization of voluntary movements in man. Journal of Neurophysiology, 43, 118-136.

Rubin, S. R., Van Petten, C., Glisky, E. L., \& Newberg, W. (1999). Memory conjunction errors in younger and older adults: Event-related potential and neuropsychological data. Cognitive Neuropsychology, 16, 459-488.

Schloerscheidt, A., \& Rugg, M. D. (1997). Recognition memory for words and pictures: An event-related potential study. NeuroReport, 8, 3281-3285.

Schnitzler, A., Salenius, S., Salmelin, R., Jousmaki, V., \& Hari, R. (1997). Involvement of primary motor cortex in motor imagery: A neuromagnetic study. Neuroimage, 6, 201-208.

Senkfor, A. J., \& Gabrieli, J. D. E. (in preparation). Episodic action memory: Recapitulation of action events revealed by fMRI.

Senkfor, A. J., \& Van Petten, C. (1998). Who said what? An event-related potentials investigation of source and item memory. Journal of Experimental Psychology: Learning, Memory, and Cognition, 24, 1005-1025.

Senkfor, A. J., Van Petten, C., \& Kutas, M. (submitted). A source is a source of course of course? An ERP analysis of item and source memory following action and non-action encoding tasks.

Slamecka, N. J., \& Graf, P. (1978). The generation effect: Delineation of a phenomena. Journal of Experimental Psychology: Learning, Memory and Cognition, 4, 592-604.

Stephan, K. M., Fink, G. R., Passingham, R. E., Silbersweig, D., Ceballos-Bauman, A. O., Frith, C. D., \& Frackowiak, R. S. (1995). Funtional anatomy of the mental representation of upper extremity movements in healthy subjects. Journal of Neurophysiology, 73, 373-386.

Swick, D., \& Knight, R. T. (1997). Event-related potentials differentiate the effects of aging on word and non-word repetition in explicit and implicit memory tasks. Journal of Experimental Psychology, Learning, Memory, and Cognition, 23, 123-142.

Symons, C. S., \& Johnson, B. T. (1997). The self-reference effect in memory: A meta-analysis. Psychological Bulletin, 121, 371-394.

Trott, C. T., Friedman, D., Ritter, W., \& Fabiani, M. (1997). Item and source memory: Differential age effects revealed by event-related potentials. NeuroReport, 8, 3373-3378.

Tulving, E. (1972). Episodic and semantic memory. In E. Tulving \& W. Donaldson (Eds.), Organization and memory (pp. 381-403). New York: Academic Press.

Van Petten, C., \& Senkfor, A. J. (1996). Memory for words and novel visual patterns: Repetition, recognition, and encoding effects in the event-related potential. Psychophysiology, 33, 491-506.

Van Petten, C., Senkfor, A. J., \& Newberg, W. (2000). Memory for drawings in locations: Spatial source memory and event-related potentials. Psychophysiology, 37, 551-564.

Wagner, A. D., Poldrack, R. A., Eldridge, L. L., Desmond, J. E., Glover, G. H., \& Gabrieli, J. D. (1998). Material-specific lateralization of prefrontal activation during episodic encoding and retrieval. NeuroReport, 9, 3711-3717.

Wilding, E., \& Rugg, M. D. (1996). An event-related potential study of recognition memory with and without retrieval of source. Brain, 119, 889-906.

Wilding, E. L., \& Rugg M. D. (1997). An event-related potential study of memory for words spoken aloud or heard. Neuropsychologia, 35, 1185-1195. 